

\title{
Effect of Texture of Antireflection Layer on Photovoltaic Performance of Silicon/PEDOT:PSS Hybrid Solar Cells
}

\author{
Yuuki Sugano $^{1}$, Keisuke Sato ${ }^{*}$, Naoki Fukata ${ }^{2}$, Kenji Hirakuri $^{1}$ \\ ${ }^{1}$ Department of Electrical and Electronic Engineering, Tokyo Denki University, Tokyo, Japan \\ ${ }^{2}$ International Center for Materials Nanoarchitectonics, National Institute for Materials Science, Ibaraki, Japan
}

*Corresponding author: Keisuke Sato, Department of Electrical and Electronic Engineering, Tokyo Denki University, 5 Senju-Asahi-cho, Adachi-ku, Tokyo 120-8551, Japan, Tel: +81-3-5284-5406; E-mail: satok@mail.dendai.ac.jp

\begin{abstract}
High-efficiency and low-cost silicon (Si)/organic hybrid solar cells have attracted significant attention as key devices to resolve global environmental problems, and also to enhance commercial usage. Herein, we report the correlation between the texture of the antireflection layer of hybrid solar cells composed of high-density textured Si and poly(3,4-ethylenedioxythiophene):poly(styrenesulfonate) (PEDOT:PSS) and their photovoltaic performance. The 'micro-desert' and 'honeycomb' textured configurations on the Si surface provide an excellent antireflection capability for the incident wavelength range of 500-1000 nm, endowing the cells with a remarkably low reflectance value below $11 \%$. The photovoltaic performance is strongly influenced by the morphology of such an antireflection layer. In comparison with the honeycomb configuration hybrid solar cells, the micro-desert textured cells exhibit a good photovoltaic performance and a high power conversion efficiency of $5.43 \%$, due to the uniform adhesion of the PEDOT:PSS layer on the textured surface and the effective collection of the separated charge carriers at the electrodes after a post-annealing process at $200^{\circ} \mathrm{C}$. These findings contribute to technical knowledge for the development of highly efficient hybrid solar cells with an antireflection layer.
\end{abstract}

Received date: February 16, 2017

Accepted date: March 27, 2017

Published date: April 06, 2017

Citation: Sato, K., et al. Effect of Texture of Antireflection Layer on Photovoltaic Performance of Silicon/PEDOT:PSS Hybrid Solar Cells. (2017) J Nanotechnol Material Sci 4(1): 6- 13 .

DOI: $10.15436 / 2377-1372.17 .1365$

Keywords: Inorganic/organic hybrid solar cells; Micro-desert texture; Honeycomb configuration; Conjugated conducting polymer; Photovoltaic performance

\section{Introduction}

The energy market has destabilized with the increased economic development of emerging countries, owing to higher global energy demands and an increase in the cost of fossil fu$\mathrm{els}^{[1]}$. In addition, the seriousness of global environmental issues, such as the emission of greenhouse gases and the frequency of abnormal weather, has grown increasingly severe ${ }^{[2]}$. To resolve these issues, solar photovoltaic systems, which are a renewable energy source, have attracted attention worldwide ${ }^{[3,4]}$. One advantage of photovoltaic power generation is that, relative to other renewable energy sources, it can be used to create electricity everywhere ${ }^{[5]}$. Recently, inorganic/organic hybrid solar cells that combine silicon (Si) with poly(3,4-ethylenedioxythiophene): poly(styrenesulfonate) (PEDOT: PSS) have gained increasing attention as next-generation solar cells because of their simple manufacturing process and inexpensive fabrication approach ${ }^{[6,7]}$. However, there are some problems that must be solved towards the practical use of such inorganic/organic hybrid solar cells. In the past several years, significant research efforts have been made to maximize the power conversion efficiency (PCE) of these cells. Thus, current research has focused on the introduction of a textured configuration on the Si surface of hybrid solar cells ${ }^{[8-10]}$. A textured configuration can provide potentially effective tools for reducing reflectance, which is closely related to the generation rate of charge carriers in hybrid solar cells, and also to their corresponding photovoltaic performance. As a matter of fact, we have previously proved that a micro-pyramidal-structured Si surface, which is a widely used texture configuration, is effective in reducing the reflectance to a value of $21-28 \%$ in the incident wavelength range of $500-1000 \mathrm{~nm}$, compared to a planar Si surface, which has a reflectance of $33-40 \%{ }^{[11]}$. 
The reduced reflectance of the hybrid solar cells that had the micro-pyramidal surfaces significantly contributed to the increased PCE value of $8.25 \%$, in comparison to the PCE value of $1.72 \%$ of planar hybrid solar cells ${ }^{[11]}$. Therefore, the construction of an optimal textured configuration can induce conditions conducive to the enhancement of antireflection capabilities and PCE values. For instance, the reflectance of a Si surface with fine asperity shapes enabled the further reduction, in comparison with micro-pyramidal-structured surfaces. This is due to the increased effective optical path length of incident light in the fine asperity structures as a result of light trapping and scattering. Recently, Tsujino and Matsumura et al. reported that Si solar cells without conducting polymers and with a microporous layer (approximately $6 \mu \mathrm{m}$ deep and with a pore size of about $1 \mu \mathrm{m}$ ) on the $\mathrm{Si}$ surface, induced a reflectance of less than $10 \%$ in the incident wavelength range of $500-1000 \mathrm{~nm}$, and produced a high PCE value of $16.6 \%$, compared to micro-pyramidal structures ${ }^{[12]}$.

In this study, we prepared Si/PEDOT:PSS hybrid solar cells with two types of micro-textured structures, the 'micro-desert textured configuration' and 'honeycomb configuration', using the acid chemical etching technique. In particular, we focused on the correlation between the texture of the antireflection layer and the photovoltaic performance of these hybrid solar cells. The difference in the textured configurations on the Si surface had a significant influence on the adhesiveness of the PEDOT:PSS layer at the $\mathrm{p} / \mathrm{n}$ junction interface, which caused the separation of charge carriers. Additionally, annealing at $200^{\circ} \mathrm{C}$ of the as-prepared hybrid solar cells with a uniform PEDOT:PSS coverage contributed to improving the collection rate of the separated charge carriers at the electrodes, thereby leading to an increased PCE.

\section{Materials and Methods}

\section{Materials}

One-side-polished 525- $\mu \mathrm{m}$-thick n-type crystalline $\mathrm{Si}$ (100) substrates with a resistivity of $1-50 \Omega \mathrm{cm}$ were purchased from Kojundo Chemical Laboratory Co. Acetone, ethanol, sulfuric acid $\left(\mathrm{H}_{2} \mathrm{SO}_{4}\right)$, hydrogen peroxide $\left(\mathrm{H}_{2} \mathrm{O}_{2}\right)$, hydrofluoric $(\mathrm{HF})$ acid, nitric $\left(\mathrm{HNO}_{3}\right)$ acid, silver perchlorate $\left(\mathrm{AgClO}_{4}\right)$ and sodium hydroxide $(\mathrm{NaOH})$ were acquired from Wako Pure Chemical Industries Co. PEDOT:PSS (Clevios PH1000, Leverkusen, Germany) was purchased from Heraeus. Dimethyl sulfoxide(DMSO), and Zonyl fluorosurfactant were obtained from Sigma-Aldrich. Silver (Ag) and aluminum (Al) targets were obtained from Kojundo Chemical Laboratory Co. All chemicals were used without further purification.

\section{Preparation of micro-desert textured and honeycomb con- figurations onto the surface of the Si substrates}

The Si substrates $\left(15 \times 15 \mathrm{~mm}^{2}\right)$ were first cleaned with acetone, ethanol and deionized water for $10 \mathrm{~min}$ each, followed by cleaning with a piranha solution consisting of $\mathrm{H}_{2} \mathrm{SO}_{4}$ and $\mathrm{H}_{2} \mathrm{O}_{2}(3: 1, \mathrm{v} / \mathrm{v})$ for $10 \mathrm{~min}$, and a $2 \% \mathrm{HF}$ solution for $2 \mathrm{~min}$ to remove any organic compounds and native oxides. This cleaning process is of crucial importance since any residue products on the substrate's surface could prevent the uniform formation of the micro-textured structures. To investigate the effect of the texture of the antireflection layer on the photovoltaic performance of the micro-textured hybrid solar cells, two types of micro-tex- tured structures were fabricated on the substrate's surface. The first structure was the micro-desert textured configuration, which was produced on the substrate's surface at room temperature by using a simplified and cheap version of the vapor acid chemical etching (VACE) technique, in which only one piece of substrate and $2 \mathrm{~mL}$ of a $\mathrm{HF} / \mathrm{HNO}_{3}$ mixed solution were hermetically sealed in a polymeric container (without a vacuum) for $24 \mathrm{~h}^{[13]}$. When using the VACE technique, ammonium hexafluorosilicate $\left(\left(\mathrm{NH}_{4}\right)_{2} \mathrm{SiF}_{6}\right)$ microparticles were formed on the micro-desert textured configuration ${ }^{[13]}$. In this study, the micro-desert textured configuration was obtained by dissolving the microparticles in pure water for $10 \mathrm{~min}$.

The second micro-texture was the honeycomb configuration. This was prepared on the substrate's surface at room temperature by using the two-step metal-assisted chemical etching (MACE) technique ${ }^{[12-14]}$. First, the substrate was dipped in an aqueous solution containing $0.02 \mathrm{~mL}$ of $40 \% \mathrm{AgClO}_{4}, 0.02 \mathrm{~mL}$ of $50 \% \mathrm{NaOH}$ and $100 \mathrm{~mL}$ of pure water for $20 \mathrm{~min}$ to deposit the Ag nanoparticles. Afterward, the honeycomb configuration was produced on the substrate's surface by immersing it in an etchant consisting of $2.2 \mathrm{~mL}$ of $46 \% \mathrm{HF}, 1 \mathrm{~mL}$ of $60 \% \mathrm{H}_{2} \mathrm{O}_{2}$, and $7.8 \mathrm{~mL}$ of pure water for $5 \mathrm{~min}$. Following its fabrication, the substrate was dipped in a $1 \mathrm{wt} . \% \mathrm{NaOH}$ solution for $10 \mathrm{~min}$ to widen the pore size. Thereafter, any residues of the Ag catalyst in the interstices between each hole were completely removed using a $60 \mathrm{wt} \%$ concentrated $\mathrm{HNO}_{3}$ solution for 5 min. Using these processes, metal-free honeycomb configurations were formed.

\section{Fabrication of Si/PEDOT:PSS hybrid solar cells with mi- cro-desert textured and honeycomb configurations}

Schematic diagrams of Si/PEDOT:PSS hybrid solar cells with micro-desert textured and honeycomb configurations are illustrated in Figures 1a and 1d, respectively. Firstly, the Si substrates with the micro-textured structures were cleaned with piranha solution for $50 \mathrm{~min}$, followed by their immersion in a $2 \% \mathrm{HF}$ solution for $2 \mathrm{~min}$. Immediately after the cleaning process, highly conductive PEDOT:PSS mixed with $5 \mathrm{wt} \%$ DMSO and $0.1 \mathrm{wt} \%$ Zonyl fluorosurfactant was spin-coated onto the micro-desert textured surfaces (Figure 1a) and honeycomb surfaces (Figure 1d) at a spin speed of $7500 \mathrm{rpm}$ for $120 \mathrm{~s}$, in an atmospheric environment, to form the hybrid solar cells. This process was followed by annealing the sample at $140^{\circ} \mathrm{C}$ for 30 $\mathrm{min}$, in an atmospheric environment, to remove any residual water inside the PEDOT:PSS. The strongly acidic PSS component in the PEDOT:PSS is generally known to be hygroscopic and the takes up water easily from the atmosphere, leading to the deterioration of stability of the hybrid solar cells by the increase in sheet resistance ${ }^{[15,16]}$. The humidity stability of the PEDOT:PSS dramatically improves by the addition of secondary dopants, such as DMSO and ethylene glycol, and the thermal annealing because of the reduced uptake of water by the depletion of PSS $^{[15,16]}$. Owing to the usage of the stable PEDOT:PSS in an atmospheric environment by introducing these approaches in this study, the top surface in our hybrid solar cells did not seal with a resin. To complete the photovoltaic structures, 200-nm-thick Ag finger-grid front and Al rear electrodes were formed on the surface of the PEDOT:PSS layer, and the backside of the Si substrate, respectively, by radio frequency (RF) sputtering through a shadow mask. The width of each finger of the Ag grid electrode 
was $100 \mu \mathrm{m}$, and the spacing between fingers was $500 \mu \mathrm{m}$. The PEDOT:PSS used in this study has conductivity as high as $900-$ $1000 \mathrm{~S} \mathrm{~cm}^{-1}$ owing to the addition of secondary dopants, such as DMSO $^{[17,18]}$. This implies that most of hole in the PEDOT:PSS layer can be laterally transferred between the Ag fingers with spacing of $500 \mu \mathrm{m}$. We have previously attained the high PCE of $9.3 \%$ for vertically aligned Si nanowire/PEDOT:PSS hybrid solar cells with such Ag finger-grid front electrode ${ }^{[19]}$. Thus, although the spacing of $500 \mu \mathrm{m}$ between the Ag fingers is sufficient for the hole collection at Ag electrode, the reduction in the spacing might be further improved the collection rate of hole.

\section{Characterization}

Scanning electron microscopy (SEM) observations were used for the morphology analysis of the two types of micro-textured Si substrates and Si/PEDOT:PSS composites. The reflectance of the planar Si substrate, and micro-textured Si substrate with and without PEDOT:PSS coverage, were recorded by a JASCO V-770 ultraviolet/visible/near-infrared (UV/vis/NIR) spectrophotometer system coupled with an integrating sphere. The cell performance and current density-voltage characteristics of the micro-textured Si/PEDOT:PSS hybrid solar cells were measured at room temperature using a Keithley 2400 source meter, under the illumination of $100 \mathrm{~mW} / \mathrm{cm}^{2}$ simulated solar light using an air mass (AM) of $1.5 \mathrm{G}$, which was calibrated using a single-crystalline silicon solar cell (BS-500) provided by Sharp.

\section{Results and Discussion}

\section{Morphology and antireflection effect of Si/PEDOT:PSS com- posites with micro-desert textured and honeycomb configu- rations}

The morphology of the antireflection layer on the $\mathrm{Si}$ substrate surface was confirmed by using top-view and cross-sectional SEM micrographs, as shown in Figures 1b, 1c, 1e, 1f. In the micro-desert textured structures, bumpy surfaces were found to be uniformly distributed over the entire region of the Si substrate (Figures $1 \mathrm{~b}$ and $1 \mathrm{c}$ ). The average width and height of the obtained micro-desert textures were approximately $0.46 \mu \mathrm{m}$ and $0.52 \mu \mathrm{m}$, respectively (Figure 1c). The fine asperity micro-desert textures could be easily produced by changing the etchant from an alkaline solution (e.g., potassium hydroxide $(\mathrm{KOH})$ ), which was used for the formation of the micro-pyramidal structures, to an acid solution (e.g., $\mathrm{HF}$ and $\mathrm{HNO}_{3}$ ). However, it appeared that such chemical etching made it difficult to realize the micropore shapes, which are effective for the antireflection layer. In contrast, the MACE technique, using the metallic catalyst (Ag nanoparticles with a mean diameter of $100 \mathrm{~nm}$ formed by using an aqueous solution of $\mathrm{AgClO}_{4}$ and $\mathrm{NaOH}$ ) and the etchant (e.g., $\mathrm{HF}$ and $\mathrm{H}_{2} \mathrm{O}_{2}$ ), could uniformly form honeycomb structures with cylindrical micropore shapes consisting of an average pore size of approximately $0.5 \mu \mathrm{m}$, and an average depth of approximately $1.8 \mu \mathrm{m}$, over the entire surface of the Si substrate (Figures 1e and 1f). The cylindrical micropore shapes were produced with the assistance of the catalytic Ag nanoparticles that were deposited directly on the substrate's surface. The catalytic action contributed to the activation of the oxidative reaction of the localized region of $\mathrm{Si}$ underneath the $\mathrm{Ag}$ nanoparticles by generating holes $\left(\mathrm{h}^{+}\right)$at the $\mathrm{Si} / \mathrm{Ag}$ nanoparticles interface region. This was due to the oxidative reaction caused by the extraction of electrons in the localized region of $\mathrm{Si}$, which was due to the reduction reaction between the $\mathrm{Ag}$ nanoparticles and $\mathrm{H}_{2} \mathrm{O}_{2}$ in the etchant. As a result, the oxidized region of the $\mathrm{Si} / \mathrm{Ag}$ nanoparticle interface was selectively dissolved in HF in the etchant, thereby forming honeycomb structures with cylindrical micropore shapes. For the Si substrate with such micro-textured surfaces, the PEDOT:PSS layer, which is a p-type-like conjugated conducting polymer, was spin-coated at a spin speed of $7500 \mathrm{rpm}$. We have previously confirmed that for micro-pyramidal structures ${ }^{[1]}$ and nanowire array structures ${ }^{[19]}$ this spin speed enables the PEDOT:PSS layer to better adhere on micro-textured surfaces.
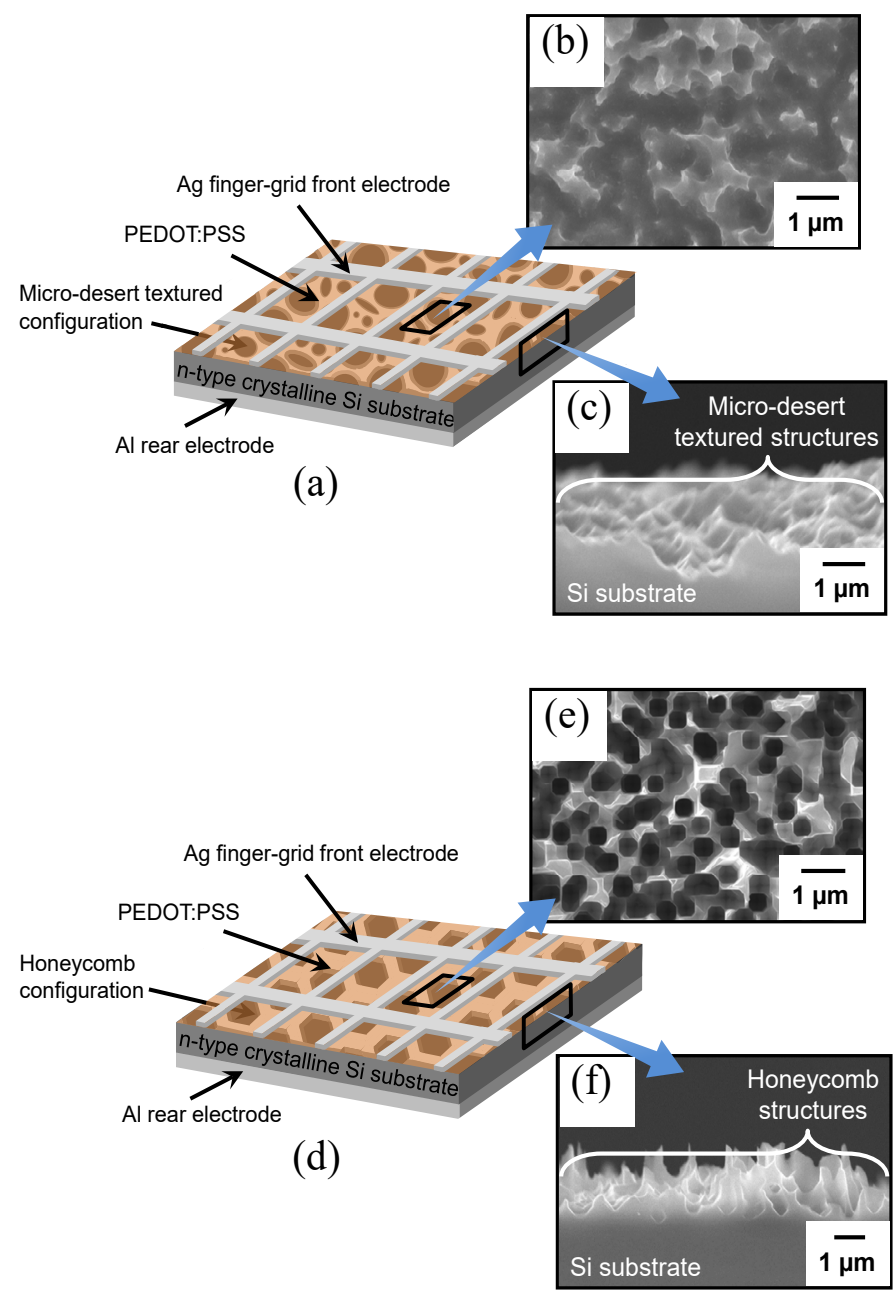

Figure 1: (a) Schematic diagrams of the Si/PEDOT:PSS hybrid solar cell with micro-desert textured structures. (b) Top-view and (c) cross-sectional SEM images of the micro-desert textured structures on the substrate's surface. (d) Schematic diagrams of the Si/PEDOT:PSS hybrid solar cell with honeycomb structures. (e) Top-view and (f) cross-sectional SEM images of the honeycomb structures on the substrate's surface.

The morphology of the PEDOT:PSS layer on the micro-desert textured surfaces and honeycomb surfaces was analyzed by means of cross-sectional SEM micrographs, as shown in Figures $2 \mathrm{a}$ and $2 \mathrm{~b}$, respectively. The adhesiveness of the PEDOT:PSS coverage strongly depended on the configuration of the antireflection layer on the substrate's surface. Due to the enhanced centrifugal and capillary forces, the bumpy surfaces in the micro-desert textured structures of the fine asperity shapes with low height (Figure 2a) could be smoothly covered with the PEDOT:PSS layer because the penetration rate of PEDOT:PSS 
exceeded the hardening rate. The average thickness $\left(\mathrm{T}_{\text {ave }}\right)$ of the PEDOT:PSS layer on the micro-desert textured surfaces was approximately $18 \mathrm{~nm}$. However, with a spin speed of $7500 \mathrm{rpm}$ it was difficult to uniformly coat the PEDOT:PSS layer on complicated configurations with a depth of more than $1 \mu \mathrm{m}$. The honeycomb structures with cylindrical micropore shapes were hardly able to transfuse PEDOT:PSS toward narrow valleys inside the micropore during the spin coating process. In such cases, the PEDOT:PSS layer with a $\mathrm{T}_{\text {ave }}$ of approximately $20 \mathrm{~nm}$ rapidly cured around the upper part of the cylindrical micropore (Figure 2b). As a result, great voids, which have major adverse effects on the separation rate of the photo-generated charge carriers, and also on the photovoltaic performance, were formed in the inner regions of all cylindrical micropores (Figure $2 b$ ). Therefore, these results show that the configuration of the micro-textures had a considerable influence on the adhesiveness of the PEDOT:PSS layer over the entire region of the micro-textured surfaces. Additionally, it was also found that the micro-desert textured structures provided the best adhesion for the PEDOT:PSS layers. The antireflection capability of the micro-textured structures on the Si substrate's surface was demonstrated by reflectance analysis, as shown in Figure 3a. For the purpose of comparison, the same experiments were also done for a planar Si substrate. For all $\mathrm{Si}$ substrates, the reflection peaks were observed in the UV region of approximately $270 \mathrm{~nm}$ and approximately $370 \mathrm{~nm}$. These peaks at around $370 \mathrm{~nm}$ and $270 \mathrm{~nm}$ are caused by E1 and E2 transitions (direct interband transitions) of $\mathrm{Si}$, respectively ${ }^{[20,21]}$. These reflection peaks dramatically decreased by forming the micro-textured structures on the Si substrate's surface. The decrease in the reflectance arises from the diffraction effects of the incident light, which occur when the wavelength of the incident light was comparable to that of the periodicity of the micro-textured surfaces ${ }^{[20,21]}$. Additionally, the planar Si substrate exhibited a strong reflectance of more than $70 \%$ in the incident wavelength range above $1100 \mathrm{~nm}$ corresponding to the optical band edge of $\mathrm{Si}$. However, the reflectance was reduced to below $40 \%$ in the incident wavelength range of $500-1000 \mathrm{~nm}$. As expected, the reflectance was dramatically suppressed by introducing micro-textured structures with fine asperity shapes on the Si substrate's surface. The Si substrate with the micro-desert textured surface showed the low reflectance, with a value of less than $11 \%$, in the same wavelength range. This low reflectance is attributed to the increased effective optical path length of incident light in the micro-desert textures due to light trapping and collective light scattering. When fabricating the honeycomb structure on the substrate's surface, the reflectance dropped to a value lower than $6 \%$ in the same wavelength range. This remarkably low reflectance is due to the dynamization of the sub-wavelength light trapping and collective light scattering within the cylindrical micropore by the formation of complicated configurations with a depth of more than $1 \mu \mathrm{m}$. Thus, these micro-textured surfaces could provide an excellent antireflection capability. It is particularly worth noting that the antireflection effect could be further promoted by the PEDOT:PSS coverage onto the micro-textured surfaces. The reflectance properties of the micro-textured structures after the PEDOT:PSS coating are shown in Figure 3b. For the purpose of comparison, the same experiments were also done for a planar Si/PEDOT:PSS composite. The micro-desert textured structure after the PEDOT:PSS coating exhibited a reflectance lower than $9.6 \%$ in the incident wavelength range of $500-1000$ $\mathrm{nm}$. This value is lower than that before the PEDOT:PSS coat- ing. In contrast, the reflectance of the honeycomb structure after the PEDOT:PSS coating was nearly equal to that before the PEDOT:PSS coating in the same wavelength range. The further suppression of the reflectance was achieved through the support of the PEDOT:PSS layer, which had absorption in the UV and NIR regions, because the PSS component in the PEDOT:PSS layer has an intense absorbance in the UV region (an absorption peak around $225 \mathrm{~nm})^{[22]}$, and the PEDOT component presents a broad absorbance in the NIR region (an absorption peak of around $800-3000 \mathrm{~nm})^{[23]}$. Therefore, these results demonstrate that the control of both the configuration of the micro-textures and the PEDOT:PSS coverage onto the micro-textured surfaces can maximize the antireflection capability.
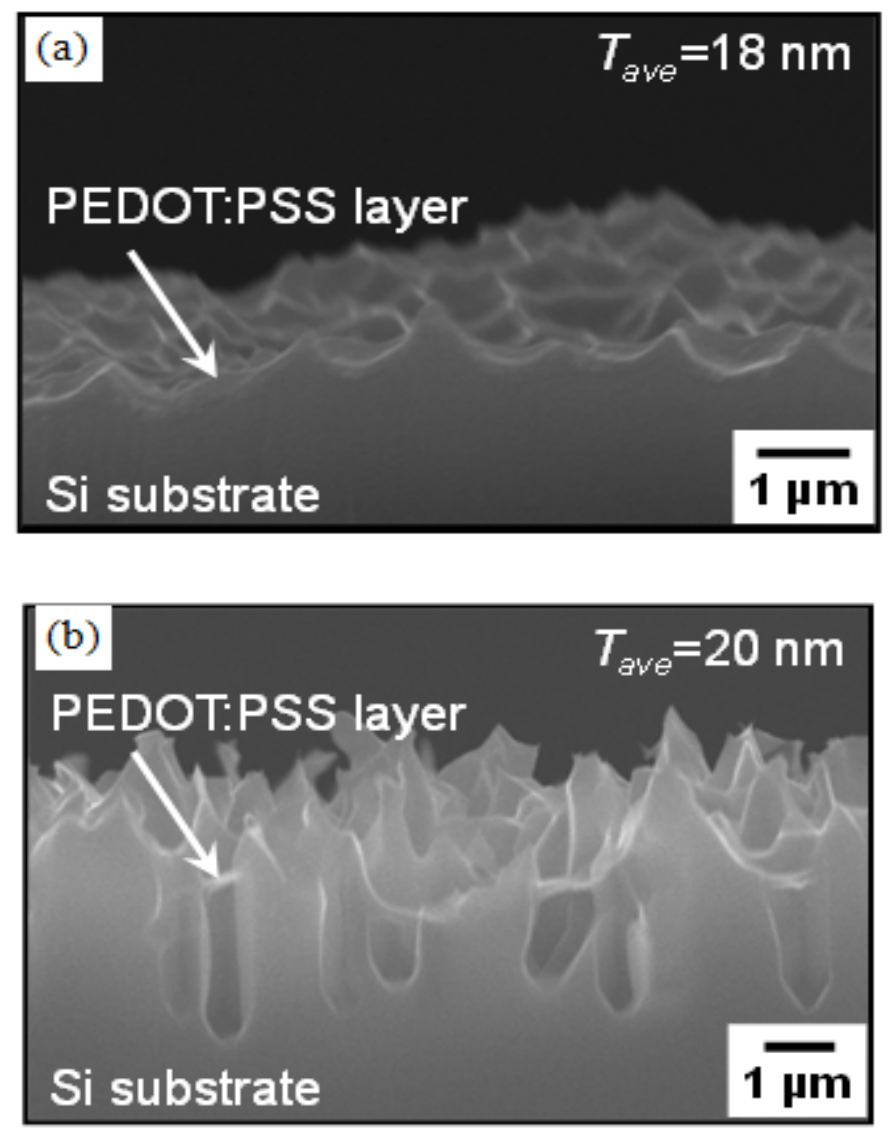

Figure 2: Cross-sectional SEM images of the PEDOT:PSS layer on (a) micro-desert textured surfaces, and (b) honeycomb surfaces coated using spin speeds of $7500 \mathrm{rpm}$. $\mathrm{T}_{\text {ave }}$ is the an average thickness of the PEDOT:PSS layer for each textured structure.

(a)






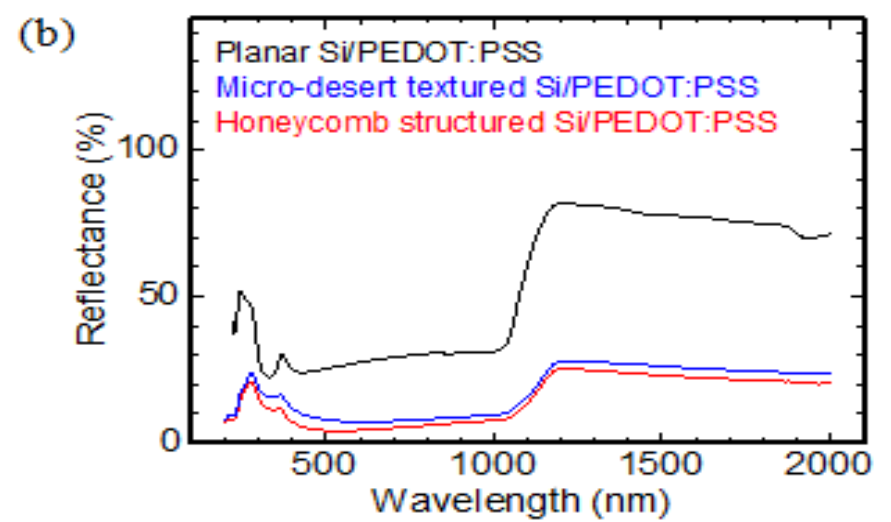

Figure 3: Reflectance spectra of the planar Si substrate, micro-desert textured Si substrate, and honeycomb structured Si substrate (a) before and (b) after PEDOT:PSS coverage. Each Si/PEDOT:PSS composite in (b) was fabricated by coating PEDOT:PSS at a spin speed of $7500 \mathrm{rpm}$.

Effect of the texture of the antireflection layer in $\mathrm{Si} / \mathrm{PE}$ DOT:PSS hybrid solar cells with micro-desert textured and honeycomb surfaces

To clarify the effect of the texture of the antireflection layer on the photovoltaic performance of the micro-textured $\mathrm{Si} /$ PEDOT:PSS hybrid solar cells, the current density-voltage characteristics were measured under $100 \mathrm{~mW} / \mathrm{cm}^{2}$ AM $1.5 \mathrm{G}$ solar illumination, as shown in Figure 4a. The corresponding photovoltaic parameters of these cells, such as a short circuit current density $\left(\mathrm{J}_{\mathrm{sc}}\right)$, open circuit voltage $\left(\mathrm{V}_{\mathrm{oc}}\right)$, fill factor $(\mathrm{FF})$, and PCE are summarized in Table 1. The micro-desert textured Si/PEDOT:PSS hybrid solar cell showed a good performance with a high $\mathrm{V}_{\mathrm{oc}}$ value of $0.480 \mathrm{~V}$, a FF of 0.436 , and a PCE value of $4.94 \%$; however, its $\mathrm{J}_{\mathrm{sc}}$ value of $23.6 \mathrm{~mA} / \mathrm{cm}^{2}$ was low (Figure 4a and Table 1). This hybrid solar cell was found to possess a low reflectance value below $9.6 \%$ over the broad spectrum of $500-1000 \mathrm{~nm}$ by the antireflection effect, as identified by the reflectance analysis in Figure $3 \mathrm{~b}$. In addition, it enabled for good adhesion between the micro-desert textures and the PEDOT:PSS layer, as identified by the SEM analysis in Figure 2a. These advantages of the hybrid solar cell allowed for the efficient generation of charge carriers in the micro-desert textured $\mathrm{Si} / \mathrm{PE}$ DOT:PSS regions, and also the effective separation of charge carriers at the appropriate $\mathrm{p} / \mathrm{n}$ junction interface corresponding to $S$ i/PEDOT:PSS. As a result, the separated holes were promptly collected at the Ag finger-grid front electrode through the PEDOT:PSS layer because of the short transfer pathway between the PEDOT:PSS layer and front electrode. In contrast, the separated electrons had to travel a long distance between the Si region and $\mathrm{Al}$ rear electrode. This implies that the recombination of the separated electrons with the holes was facilitated during the transport to the rear electrode. Thus, the micro-desert textured hybrid solar cell showed a low $\mathrm{J}_{\text {sc }}$ value owing to the reduced collection rate of the separated electrons at the rear electrode by the occurrence of carrier recombination. In contrast to the $\mathrm{J}_{\mathrm{sc}}$ value, the high $\mathrm{V}_{\text {oc }}$ value was related to the high shunt resistance $\left(\mathrm{R}_{\mathrm{sh}}\right)$, which caused low power losses in the hybrid solar cells ${ }^{[19]}$, whereas the high FF arose from the low series resistance $\left(\mathrm{R}_{\mathrm{s}}\right)$. The micro-desert textured hybrid solar cell had a high $\mathrm{R}_{\mathrm{sh}}$ value of $5.41 \times 10^{1} \Omega \mathrm{cm}^{2}$, and a low $\mathrm{R}_{\mathrm{s}}$ value of $1.15 \Omega \mathrm{cm}^{2}$ in comparison with the honeycomb structured cell because of the complete adhesion of the PEDOT:PSS layer throughout the micro-desert textures. Due to the possession of the high $\mathrm{V}_{\text {oc }}$ and FF, the mi- cro-desert textured hybrid solar cell accomplished a high PCE.

(a)

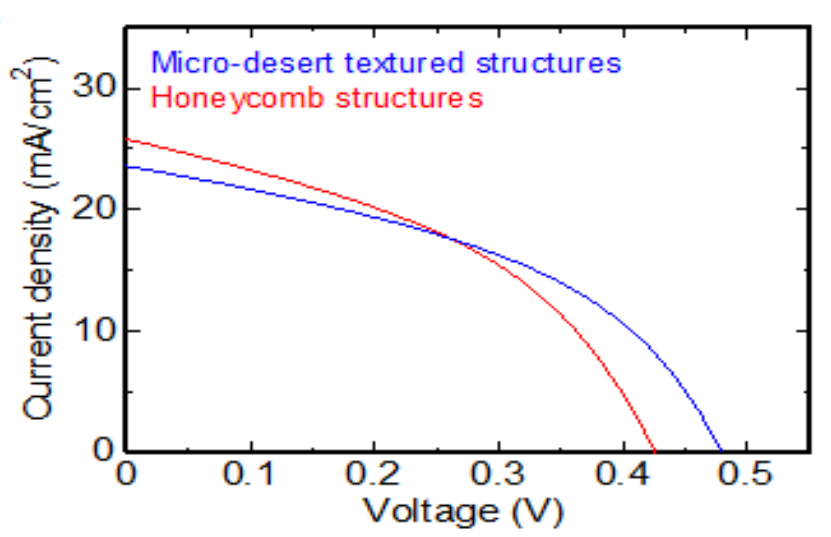

(b)

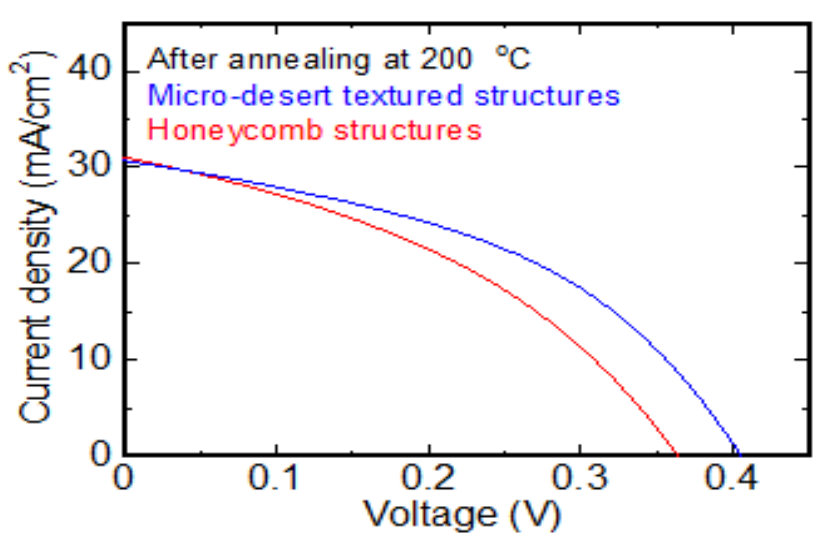

Figure 4: Current density-voltage characteristics of the micro-desert textured Si/PEDOT:PSS hybrid solar cell and honeycomb structured Si/PEDOT:PSS hybrid solar cell (a) before and (b) after annealing at $200^{\circ} \mathrm{C}$. All the hybrid solar cells were fabricated by coating PEDOT:PSS at a spin speed of $7500 \mathrm{rpm}$.

Unfortunately, the honeycomb structured $\mathrm{Si} / \mathrm{PE}$ DOT:PSS hybrid solar cell, which possessed superior antireflection capabilities, exhibited a bad performance with low $\mathrm{V}_{\mathrm{oc}}, \mathrm{FF}$, and PCE values of $0.426 \mathrm{~V}, 0.424$, and $4.66 \%$, respectively, relative to the micro-desert textured cells (Figure 4a and Table 1). The demerits of this hybrid solar cell are due to the great voids that were present in the inner regions of the cylindrical micropores, as identified by the SEM analysis in Figure $2 \mathrm{~b}$. In the hybrid solar cell containing the voids, the $\mathrm{R}_{\mathrm{sh}}$ was lowered to $4.08 \times$ $10^{1} \Omega \mathrm{cm}^{2}$, while the $\mathrm{R}_{\mathrm{s}}$ rose to $1.50 \Omega \mathrm{cm}^{2}$ compared to the micro-desert textured cells owing to the deficient coverage of the PEDOT:PSS layer inside the wall of the cylindrical micropores. Yang, Liu, and Du et al., have reported on the influence of voids on the photovoltaic performance of micro-pyramidal-structured Si/PEDOT:PSS hybrid solar cells. They have also suggested that the occurrence of the voids at the Si/PEDOT:PSS interface is likely to form local shunts, which cause the deterioration of the $\mathrm{V}_{\text {oc }}$ and FF values ${ }^{[24]}$. From these factors, the honeycomb structured hybrid solar cell resulted in low $\mathrm{V}_{\mathrm{oc}}$ and $\mathrm{FF}$ values, thereby leading to the degradation of the PCE. Intriguingly, the hybrid solar cell had a high $\mathrm{J}_{\mathrm{sc}}$ value of $25.8 \mathrm{~mA} / \mathrm{cm}^{2}$ (Figure $4 \mathrm{a}$ and Table 1), despite the possession of voids, which brought about a negative impact on the generation rate of the $\mathrm{p} / \mathrm{n}$ junction interface. In the hybrid solar cell with the voids, the separation of the charge carriers occurred at only the restricted junction areas of the $\mathrm{p} / \mathrm{n}$ interface, around the top and middle parts of the cy- 
lindrical micropores, where the PEDOT:PSS layer was in immediate contact with the Si layer. However, the generation rate of the charge carriers in the honeycomb structured Si/PEDOT:PSS regions was enhanced due to the superior antireflection effect, compared with the micro-desert textured hybrid solar cell. As a result, most of the separated electrons could be effectively transferred in the Si regions consisting of fine asperity shapes with cylindrical micropores, and efficiently collected at the Al rear electrode. In addition, the separated holes could be quickly collected at Ag finger-grid front electrode through the PEDOT:PSS layer. Due to the increased collection rate of the separated electrons at the rear electrode, the honeycomb structured hybrid solar cell showed a high $\mathrm{J}_{\mathrm{sc}}$ value. Regarding the stability of these hybrid solar cells, the photovoltaic performance may be affected by the features, such as humidity and UV stabilities, of the PEDOT:PSS because the top surface in our hybrid solar cells did not seal with a resin. We used the PEDOT:PSS, which not only added secondary dopants (e.g., DMSO) but also performed the thermal annealing, so as to improve the UV stability ${ }^{[25]}$ in addition to the humidity stability ${ }^{[15,16]}$, as described in the previous section. The usage of such PEDOT:PSS might be able to expected to lead to the stable photovoltaic performance in an atmospheric environment.

Table 1: Photovoltaic parameters of micro-desert textured Si/PEDOT:PSS hybrid solar cell and honeycomb structured Si/PEDOT:PSS hybrid solar cell before and after annealing at $200^{\circ} \mathrm{C}$.

\begin{tabular}{|l|l|l|l|l|l|}
\hline Device & $\begin{array}{l}\text { Annealing } \\
\text { temperature } \\
\left({ }^{\circ} \mathbf{C}\right)\end{array}$ & $\begin{array}{l}\mathbf{J}_{\text {sc }} \\
(\mathbf{m A} / \\
\left.\mathbf{c m}^{2}\right)\end{array}$ & $\begin{array}{l}\mathbf{V}_{\text {oc }} \\
(\mathbf{V})\end{array}$ & $\mathbf{F F}$ & $\begin{array}{l}\text { PCE } \\
(\mathbf{\%})\end{array}$ \\
\hline $\begin{array}{l}\text { Micro-desert } \\
\text { textured } \\
\text { structures }\end{array}$ & - & 23.6 & 0.480 & 0.436 & 4.94 \\
\hline $\begin{array}{l}\text { Honeycomb } \\
\text { structures }\end{array}$ & - & 25.8 & 0.426 & 0.424 & 4.66 \\
\hline $\begin{array}{l}\text { Micro-desert } \\
\text { textured } \\
\text { structures }\end{array}$ & 200 & 30.7 & 0.405 & 0.436 & 5.43 \\
\hline $\begin{array}{l}\text { Honeycomb } \\
\text { structures }\end{array}$ & 200 & 31.1 & 0.364 & 0.389 & 4.40 \\
\hline
\end{tabular}

Interestingly, the $\mathrm{J}_{\mathrm{sc}}$ value of the micro-textured hybrid solar cells could be further enhanced by annealing the samples at $200^{\circ} \mathrm{C}$. The photovoltaic performance of the micro-desert textured and honeycomb structured Si/PEDOT:PSS hybrid solar cells after their annealing at $200^{\circ} \mathrm{C}$ were measured under 100 $\mathrm{mW} / \mathrm{cm}^{2}$ AM $1.5 \mathrm{G}$ solar illumination, as shown in Figure $4 \mathrm{~b}$. Their corresponding photovoltaic parameters such as $\mathrm{J}_{\mathrm{sc}}, \mathrm{V}_{\mathrm{oc}}, \mathrm{FF}$, and PCE are summarized in Table 1 . The $\mathrm{J}_{\mathrm{sc}}$ of the micro-desert textured and honeycomb structured hybrid solar cells were raised to more than $30.7 \mathrm{~mA} / \mathrm{cm}^{2}$ after this annealing at $200^{\circ} \mathrm{C}$ (Figure $4 \mathrm{~b}$ and Table 1). We have previously reported that the contact resistances between the Ag front electrode and PEDOT:PSS layer, and between the Al rear electrode and the back side of Si substrate are dramatically reduced by annealing the sample at $200^{\circ} \mathrm{C}$ for vertically aligned Si nanowire/PEDOT:PSS hybrid solar cells ${ }^{[19]}$. This is because the annealing process can provide an effective tool for obtaining better adhesion between each electrode and PEDOT:PSS layer/Si substrate ${ }^{[19]}$. Moreover,
Vosgueritchian and Bao et al., have reported that the annealing process enhances the electrical conductivity of the PEDOT:PSS layer ${ }^{[17]}$. These benefits of annealing imply that the decreased contact resistance can dramatically improve the transport efficiency of the separated charge carriers between the active layer (i.e., the micro-desert textured and honeycomb structured $\mathrm{Si}$ / PEDOT:PSS composite regions) and each electrode, and also increase the collection rate of the separated charge carriers at each electrode. Thus, the substantial increase in $\mathrm{J}_{\text {sc }}$ is most likely due to a more effective carrier collection at each electrode as a result of the contact resistance decreasing (due to annealing). Additionally, after its annealing at $200^{\circ} \mathrm{C}$, the micro-desert textured hybrid solar cell showed the best performance, with the highest PCE value of $5.43 \%$, due to the significant improvement in $\mathrm{J}_{\mathrm{sc}}$ (Figure $4 \mathrm{~b}$ and Table 1). However, after its annealing, the PCE of the honeycomb structured hybrid solar cell had a slight drop to $4.40 \%$, relative to its PCE value before annealing (Figure $4 \mathrm{~b}$ and Table 1). This may be related to the deficient coverage of the PEDOT:PSS layer inside the wall of the cylindrical micropores. In contrast, the $\mathrm{V}_{\mathrm{oc}}$ of the micro-desert textured and honeycomb structured hybrid solar cells decreased to less than 0.405 $\mathrm{V}$ after their annealing at $200^{\circ} \mathrm{C}$ (Figure $4 \mathrm{~b}$ and Table 1). The decreased $\mathrm{V}_{\text {oc }}$ of these hybrid solar cells was attributable to the low $\mathrm{R}_{\text {sh }}$. The micro-desert textured and honeycomb structured hybrid solar cells had a low $\mathrm{R}_{\text {sh }}$ values of $3.86 \times 10^{1}$ and $2.94 \times$ $10^{1} \Omega \mathrm{cm}^{2}$, respectively, compared to those before their annealing. Moreover, the variation of the highest occupied molecular orbital (HOMO) energy level of the PEDOT:PSS and the work function of $\mathrm{Al}$ rear electrode by annealing can be considered as other reason for low $\mathrm{V}_{\mathrm{oc}}$ value. Liu and Kortshagen et al., have reported that the $\mathrm{V}_{\mathrm{oc}}$ value is determined by the energy difference between the HOMO energy level of the p-type conjugated conducting polymer such as PEDOT:PSS and the Fermi level of the metal when the value of the work function is larger than the electron affinity of $\mathrm{Si}^{[26]}$. The two types of hybrid solar cells before their annealing possess the electron affinity of $\mathrm{Si}$ of 4.05 $\mathrm{eV}^{[27-29]}$, the work function of $\mathrm{Al}$ of $4.3 \mathrm{eV}^{[27,30]}$, and the HOMO energy level of the PEDOT:PSS of $5.0-5.1 \mathrm{eV}^{[27,31-33]}$. In the hybrid solar cells before their annealing, the theoretical values of $\mathrm{V}_{\text {oc }}$ were estimated to be $0.7-0.8 \mathrm{eV}$. The annealing at $200^{\circ} \mathrm{C}$ might lead to the variation of the HOMO energy level of the PEDOT:PSS and the work function of Al. We have previously reported that the PEDOT:PSS layer after its annealing at $200^{\circ} \mathrm{C}$ exhibits a $15 \mathrm{wt} . \%$ weight loss owing to the endothermic decomposition of the PEDOT:PSS, causing the rearrangement of the PEDOT:PSS ${ }^{[19]}$. Moreover, Vosgueritchian and Bao et al., have reported that the rearrangement of the PEDOT:PSS changes the work function due to the increased phase separation between the PEDOT and the PSS ${ }^{[17]}$. On the other hand, the $\mathrm{Al}$ is easily oxidized by annealing at $200^{\circ} \mathrm{C}$ because of the high ionization tendency. The oxidized $\mathrm{Al}$ might be provoked the variation of the work function ${ }^{[34]}$. These benefits of annealing imply that the energy difference between the HOMO energy level of the PEDOT:PSS and the Fermi level of Al can be reduced. The reduced energy difference can result in a decrease in a $\mathrm{V}_{\text {oc }}$ values to less than $0.7-0.8 \mathrm{eV}$, which is the theoretical values of the hybrid solar cells before their annealing. Thus, the lower $\mathrm{V}_{\mathrm{oc}}$ of the annealed hybrid solar cells might be brought about by the change in composition of the PEDOT:PSS and the oxidation of Al by annealing in addition to the decreased $\mathrm{R}_{\mathrm{sh}}$. The above-mentioned 
results clearly suggest that it is important to optimize the adhesiveness of the PEDOT:PSS layer on the fine asperity shapes, in particular for honeycomb structures consisting of cylindrical micropores with a depth of more than $1 \mu \mathrm{m}$, and also perform an annealing process in order to improve the PCE of micro-textured Si/PEDOT:PSS hybrid solar cells with an antireflection layer. Consequently, we demonstrated that the best optimal configuration is that of micro-desert textures, and the most effective annealing temperature is at $200^{\circ} \mathrm{C}$, as specified in this section.

\section{Conclusion}

We demonstrated the effect that the texture of the antireflection layer had on the photovoltaic performance of hybrid solar cells consisting of micro-desert textured and honeycomb structured Si/PEDOT:PSS composites. The configuration of the antireflection layer significantly influences the adhesiveness of the PEDOT:PSS layer on the micro-textured surfaces, and also on the corresponding photovoltaic performance. The micro-desert textured surfaces allowed for the effective generation of charge carriers due to their excellent antireflection capability, and also favored the separation of charge carriers due to the better adhesiveness of the PEDOT:PSS layer. Moreover, the annealing process enabled the efficient collection of separated charge carriers at each electrode. The hybrid solar cells with the micro-desert texture surfaces achieved the best photovoltaic performance with a PCE value of $5.43 \%$. The present study provides valuable information for improving the photovoltaic performance of Si/organic polymer hybrid solar cells with a micro-textured surface.

Acknowledgment: This work was supported in part by JSPS KAKENHI Grant Number 26390105 in Japan and Research Institute for Science and Technology of Tokyo Denki University Grant Number Q15E-01 in Japan.

\section{References}

1. Caraiani, C., Lungu, C.I., Dascălu, C. Energy consumption and GDP causality: A three-step analysis for emerging European countries. (2015) Renew Sust Energy Rev 44: S198-S210.

Crossref|Others

2. Alexander, L.V., Allen, S.K., Bindoff, N.L., et al. Summary for policymakers. (2013) Climate Change 2013 The Physical Science Basis S1-S27.

Others

3. Arent, D.J. The role of renewable energy technologies in limiting climate change. (2010) The Bridge 40(3): S31-S39. Others

4. Binz, C., Tang, T., Huenteler, J. Spatial lifecycles of cleantech industries-The global development history of solar photovoltaics. (2017) Energy Policy 101: S386-S402.

Crossref| Others

5. Solangi, K.H., Islam, M.R., Saidur, R., et al. A review on global solar energy policy. (2011) Renew Sust Energy Rev 15(4): S2149-S2163.

Crossref| Others

6. Thomas, J.P., Leung, K.T. Defect-minimized PEDOT:PSS/planar-Si solar cell with very high efficiency. (2014) Adv Funct Mater 24(31): S4978-S4985.

Crossref|Others

7. Liu, R., Lee, S.T., Sun, B. $13.8 \%$ efficiency hybrid Si/organic heterojunction solar cells with $\mathrm{MoO} 3$ film as antireflection and inversion induced layer. (2014) Adv Mater 26(34): S6007-S6012.

Pubmed | Crossref| Others

8. Jeong, S., Garnett, E.C., Wang, S., et al. Hybrid silicon nanocone-polymer solar cells. (2012) Nano Lett 12(6): S2971-S2976.

Pubmed | Crossref | Others

9. Yu, P., Tsai, C.Y., Chang, J.K., et al. 13\% efficiency hybrid organic/silicon-nanowire heterojunction solar cell via interface engineering. (2013) ACS Nano 7(12): S10780-S10787.

Pubmed | Crossref | Others

10. Zhang, Y., Cui, W., Zhu, Y., et al. High efficiency hybrid PEDOT:PSS/nanostructured silicon schottky junction solar cells by doping-free rear contact. (2015) Energy Environ Sci 8(1): S297-S302. Crossref|Others

11. Sugano, Y., Sato, K., Fukata, N., Hirakuri, K. Improved separation and collection of charge carriers in micro-pyramidal-structured silicon/ PEDOT:PSS hybrid solar cells. (2017) Energies 10(4): S420.

Others

12. Tsujino, K., Matsumura, M., Nishimoto, Y. Texturization of multicrystalline silicon wafers for solar cells by chemical treatment using metallic catalyst. (2006) Sol Energy Mater Sol Cells 90(1): S100-S110. Crossref|Others

13. Sato, K., Sugano, Y., Hirakuri, K., et al. Cell performances of inorganic-organic hybrid solar cells using fluorosilicate/phosphorus oxide composite microparticles. (2017) Adv Sci Technol 98: S26-S31.

Others

14. Kortenaar, M.V., Goeij, J.J.M., Kolar, Z.I., et al. Electroless silver deposition in $100 \mathrm{~nm}$ silicon structures. (2001) J Electrochem Soc 148(1): S28-S33.

Crossref|Others

15. Nardes, A.M., Kemerink, M., Kok, M.M., et al. Conductivity, work function, and environmental stability of PEDOT:PSS thin films treated with sorbitol. (2008) Org Electron 9(5): S727-S734.

Crossref|Others

16. Kim, Y.H., Michael, C.S., Machala, M.L., et al. Highly conductive PEDOT:PSS electrode with optimized solvent and thermal post-treatment for ITO-free organic solar cells. (2011) Adv Funct Mater 21(6): S1076-S1081.

Others

17. Vosgueritchian, M., Lipomi, D.J., Bao, Z. Highly conductive and transparent PEDOT:PSS films with a fluorosurfactant for stretchable and flexible transparent electrodes. (2012) Adv Funct Mater 22(2): 


\section{S421-S428}

Crossref| Others

18. Lipomi, D.J., Lee, J.A., Vosgueritchian, M., et al. Electronic properties of transparent conductive films of PEDOT:PSS on stretchable substrates. (2012) Chem Mater 24(2): S373-S382.

Crossref|Others

19. Sato, K., Dutta, M., Fukata, N. Inorganic/organic hybrid solar cells: optimal carrier transport in vertically aligned silicon nanowire arrays. (2014) Nanoscale 6(11): S6092-S6101.

Pubmed | Crossref | Others

20. Hadobás, K., Kirsch, S., Carl, A., et al. Reflection properties of nanostructure-arrayed silicon surfaces. (2000) Nanotechnology 11(3): S161-S164.

Crossref| Others

21. Xia, Y., Liu, B., Zhong, S., et al. X-ray photoelectron spectroscopic studies of black silicon for solar cell. (2012) J Electron Spectrosc Relat Phenom 184(11-12): S589-S592.

Crossref|Others

22. Arabloo, F., Javadpour, S., Memarzadeh, R., et al. The interaction of carbon monoxide to $\mathrm{Fe}(\mathrm{III})$ (salen)-PEDOT:PSS composite as a gas sensor. (2015) Synthetic Metals 209: S192-S199.

Others

23. Wakizaka, D., Fushimi, T., Ohkita, H., et al. Hole transport in conducting ultrathin films of PEDOT:PSS prepared by layer-by-layer deposition technique. (2004) Polymer 45(25): S8561-S8565.

Crossref|Others

24. Yang, L., Liu, Y., Chen, W., et al. Interface Engineering of high efficiency organic-silicon heterojunction solar cells. (2016) ACS Appl Mater Interfaces 8(1): S26-S30.

Pubmed |Crossref| Others

25. Clevios PH1000 maker, Heraeus.

Others

26. Liu, C.Y., Holman, Z.C., Kortshagen, U.R. Optimization of Si NC/ P3HT hybrid solar cells. (2010) Adv Funct Mater 20(13): S2157-S2164.
Crossref $\mid$ Others

27. He, L., Jiang, C., Rusli, Lai, D., et al. Highly efficient Si-nanorods/ organic hybrid core-sheath heterojunction solar cells. (2011) Appl Phys Lett 99(2): S021104.

Crossref |Others

28. Lei, X., Zhang, F., Song, T., et al. p-type doping effect on the performance of organic-inorganic hybrid solar cells. (2011) Appl Phys Lett 99(23): S233305.

Crossref|Others

29. Ding, Y., Gresback, R., Liu, Q., et al. Silicon nanocrystal conjugated polymer hybrid solar cells with improved performance. (2014) Nano Energy 9: S25-S31.

Crossref| Others

30. Kuo, C.Y., Gau, C. Arrangement of band structure for organic-inorganic photovoltaics embedded with silicon nanowire arrays grown on indium tin oxide glass. (2009) Appl Phys Lett 95(5): S053302.

Crossref|Others

31. Ozdemir, B., Kulakci, M., Turan, R., et al. Silicon nanowire-poly (3,4-ethylenedioxythiophene)-poly(styrenesulfonate) heterojuncion solar cells. (2011) Appl Phys Lett 99(11): S113510.

Crossref|Others

32. Lim, D.C., Kim, K.D., Park, S.Y., et al. Towards fabrication of high-performing organic photovoltaics: new donor-polymer, atomic layer deposited thin buffer layer and plasmonic effects. (2012) Energy Environ Sci 5(12): S9803-S9807.

Crossref|Others

33. Thiyagu, S., Hsueh, C.C., Liu, C.T., et al. Hybrid organic-inorganic heterojunction solar cells with $12 \%$ efficiency by utilizing flexible film-silicon with a hierarchical surface. (2014) Nanoscale 6(6): S3361-S3366.

Pubmed |Crossref|Others

34. Zhou, Y., Cheun, H., Potscavage, W.J., et al. Inverted organic solar cells with ITO electrodes modified with an ultrathin $\mathrm{Al} 2 \mathrm{O} 3$ buffer layer deposited by atomic layer deposition. (2010) J Mater Chem 20(29): S6189-S6194.

Crossref| Others
Ommega Online Publishers

Journal Title: Journal of Nanotechnology and Materials Science Journal Short Name: J Nanotech Mater Sci
Journal ISSN: 2377-1372

E-mail: nanoscience@ommegaonline.com

Website: www.ommegaonline.org 